\title{
Uracil Ointment
}

National Cancer Institute

\section{Source}

National Cancer Institute. Uracil Ointment. NCI Thesaurus. Code C91083.

A $0.1 \%$ topical formulation of uracil used potentially to lower the incidence of hand-foot syndrome (HFS) (or palmar-plantar erythrodysesthesia) during 5-fluorouracil (5-FU) or 5FU prodrug capecitabine chemotherapy. Upon local administration of uracil ointment to the skin, uracil competes with capecitabine or 5-FU as substrates for the activating enzyme thymidine phosphorylase and the metabolizing enzyme dihydropyrimidine dehydrogenase. This may prevent the production of 5-FU as well as the breakdown of 5FU into the toxic metabolites locally. As the 5-FU metabolites are responsible for the presentation of HFS, inhibiting their formation may prevent this adverse effect. By applying a high concentration of uracil locally, the skin toxicities of 5-FU may be countered while preserving the systemic anti-cancer activity of the 5FU. 